\title{
INFLUENCE OF THERMAL STRESS RATE ON CHANGES IN ELECTRICAL INSULATING OILS
}

\author{
Peter HAVRAN, Roman CIMBALA, Juraj KURIMSKÝ, Jozef KIRÁLY, Vladimír KOHAN, Jozef HUMENÍK \\ Department of Electric Power Engineering, Faculty of Electrical Engineering and Informatics, \\ Technical University of Košice, Letná 9, 04200 Košice, Slovak Republic, \\ E-mail: peter.havran@tuke.sk, roman.cimbala@tuke.sk,juraj.kurimsky@tuke.sk,jozef.kiraly@tuke.sk, \\ vladimir.kohan@tuke.sk, jozef.humenik@student.tuke.sk
}

\begin{abstract}
This work solves the comparison of two different thermal stress times for selected liquid insulation materials based on transformer oils by impedance spectroscopy. Research is focused on actual and progressive liquid insulation materials. The scientific objectives of the experiment are focused on the determination of hypotheses, defined by predictable electrophysical parameters in experimental conditions, which are described in the analysis of the measured results.
\end{abstract}

Keywords: Cole-Cole, complex electrical modulus, Debye, impedance spectroscopy, oils, thermal stress

\section{INTRODUCTION}

The basic element that is investigated in the event of a transformer failure is its insulation. The insulation system of a power transformer consists of oil and paper that can come into contact with moisture. The increased moisture content in the transformer insulation system leads to a deterioration of the insulation properties, which leads to equipment failure if its condition is not regularly monitored without the necessary measures. This is a persistent problem due to detrimental effects on the integrity of the insulation. The reason for these undesirable processes is the changing temperature in power transformers [1]. Operating conditions related to thermal stress cause aging of individual parts of the transformer with changes in the insulation system. Economically reliable and efficient electricity supplies with a consistent and uninterrupted supply are of primary concern to energy companies worldwide [2][3]. Due to the cost pressure on the liberalized electricity market, electricity companies are forced to conditionally carry out frequent equipment maintenance. This process requires reliable diagnostic operations [4]. Appropriate diagnostics of the insulation system is one of the requirements for the safe operation of transformers, which points to the relationship between the change in the functional characteristics of the device and the actual measured data. The measured data must clearly show not only the rate of change, but also whether it is a permanent or reversible state [2]. Conventional diagnostic methods require short-term decommissioning of equipment with the implementation of minimum measures that are important for preparing the equipment for the measurement itself [5].

The main motivation for carrying out this experiment was to capture the effect of moisture in insulating oils during gradual temperature measurements on operating and higher oil temperatures, assuming that the rate of oil heating to a certain temperature can affect humidity during gradual temperature measurements to ambient temperature. This experiment aims to analyze and compare electrophysical phenomena by measuring diagnostic parameters due to the heating rate of electrical insulating oils to $90{ }^{\circ} \mathrm{C}$ with emphasis on moisture in the oil in the frequency domain of impedance spectroscopy.

The main function of the impedance spectroscopy method is the effect of the electric field on the electric dipoles contained in the dielectric material and the characteristics of their response. Frequency domain impedance spectroscopy has an investigation of the frequency dependence of the complex impedance $Z^{*}$, the complex permittivity $\mathcal{E}^{*}$, and other parameters expressed by them, such as the complex electrical modulus $M^{*}$. Impedance spectroscopy involves measuring impedance over a wide frequency range at an applied electric field strength. This is the resulting response $Z(\omega)$, which provides meaningful information about the condition and electrical properties of the insulation material. To interpret the results of the complex impedance $Z^{*}$, it can be very useful to transform the data into the complex permittivity $\varepsilon^{*}$ or the complex electrical modulus $M^{*}$ expressed from it using the relation:

$M^{*}=\frac{1}{\varepsilon^{*}}=j \omega C_{0} Z^{*}$

where $j$ is the imaginary unit, $\omega$ is the angular frequency and $C_{0}$ is the geometric capacitance of the electrode arrangement [6].

\section{EXPERIMENT}

The experiment compares two tests with different heating rates of oils. The first test represents a measurement in the frequency domain of impedance spectroscopy by heating oil samples from $20^{\circ} \mathrm{C}$ to $90{ }^{\circ} \mathrm{C}$ in $10^{\circ} \mathrm{C}$ steps and then cooling the samples from $90^{\circ} \mathrm{C}$ to $20^{\circ} \mathrm{C}$ also in $10^{\circ} \mathrm{C}$ steps. For a given measurement procedure, approximately the same waveforms of the values of the examined parameters are expected when comparing between increasing and decreasing the temperature, if the oil sample does not contain any moisture. It follows from the above that the first test includes 16 measurements in the frequency domain of impedance spectroscopy. The second test, in contrast to the first, contains measurements in the frequency domain only when the samples are cooled from 
$90{ }^{\circ} \mathrm{C}$ to $20^{\circ} \mathrm{C}$ with a temperature step of $10^{\circ} \mathrm{C}$. The second test, therefore, contains half as many measurements as the first test. The difference between the first and second test is therefore in the speed, respectively time of reaching a temperature of $90^{\circ} \mathrm{C}$. In the first test, there was a gradual increase in temperature due to 60-minute measurements, in contrast to the second test, where the temperature was reached directly at $90{ }^{\circ} \mathrm{C}$, but at a much shorter point in time than in the first test.

\subsection{Samples of examined electrical insulating oils}

The object of experimental analysis is liquid insulating materials based on mineral oils and liquefied gases (GTL oil). The experiment is carried out on new, non-aged (undamaged) samples of insulating oils, which contain certain moisture during their storage. The examined samples of insulating oils are:

- MOGUL TRAFO CZ-A, which will be referred to in the analysis of measured results as - MO,

- Shell DIALA S4 ZX-1, which will be referred to in the analysis of measured results as $-\mathbf{S D}$.

MOGUL TRAFO CZ-A is an inhibited transformer oil of light or slightly yellow colour, which has excellent electrical insulating properties. It is made from high-quality hydrocracked deep-refined base oil, which is obtained from paraffin oil using state-of-the-art technology [7]. Shell DIALA S4 ZX-1 is a transformer oil based on GTL technology from Shell, which has an extended service life with zero sulphur content and very low content of aromatic and unsaturated substances. It is a fully inhibited oil that provides excellent oxidizing performance, as a result of which it can be used even in highly loaded areas [8].

\subsection{Experimental workplace and used instruments}

Experimental measurements were performed under laboratory conditions with atmospheric air pressure. To carry out this experiment, a circuit diagram of the measuring station was designed (Fig. 1), which represented experimental measurements in the frequency domain of impedance spectroscopy.

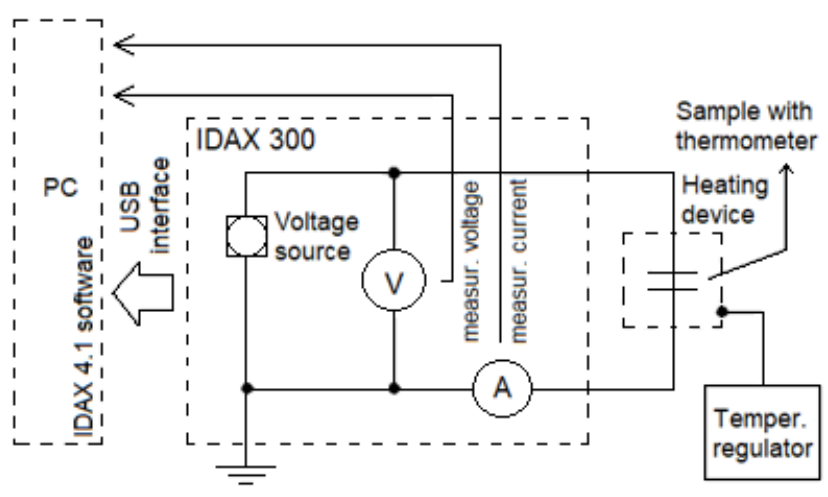

Fig. 1 Wiring diagram of the measuring circuit

The wiring diagram consists of the following devices:

- $\quad$ Tettex AG Zürich electrode system type 2903a $\left(C_{0}=\right.$ $60 p F, \quad d=2 \cdot 10^{-3} \mathrm{~m}, \quad V=40 \mathrm{ml}$ ) with built-in thermometer, stored in the Tettex AG Zürich type 2903 heating device,

- Tettex AG Zürich temperature regulator type 2965,

- wire connected from the temperature regulator to the heating device,

- IDAX 300 measurement device with communication cable via USB bus and two wires for connection to the electrode system, and

- $\quad$ portable laptop (PC).

\subsection{The course of the experiment}

The course of the experiment is explained as follows. All devices were connected according to the diagram (Fig. 1). Before measurement, the electrode system was disassembled and cleaned of any impurities, followed by storage in a professional oven at $50{ }^{\circ} \mathrm{C}$ for one hour to eliminate water particles, respectively excessive humidity. After removal from the professional oven, it was folded and cooled to room temperature. A $40 \mathrm{ml}$ sample of MOGUL oil was then applied to the prepared electrode system via a syringe from a plastic oil canister stored in the laboratory. After the elimination of air bubbles from the oil in the deaeration pump, the electrode system was closed, inserted into the heating device, and prepared for the measurement itself, which was first performed through the first test. The first measurement was performed at a temperature of $20^{\circ} \mathrm{C}$ in the frequency domain using an IDAX 300 measuring instrument. After the first measurement, the temperature regulator was set to $30{ }^{\circ} \mathrm{C}$. After heating the insulating oil to this temperature, the measurement was continued again. After each temperature increase in steps of $10{ }^{\circ} \mathrm{C}$, measurements up to $90{ }^{\circ} \mathrm{C}$ were performed, i.e. 8 measurements in the frequency domain were performed. After measuring the sample at $90{ }^{\circ} \mathrm{C}$, the first test was continued by measuring the backflow, in other words by measuring gradually decreasing the temperature in steps of $10{ }^{\circ} \mathrm{C}$ up to $20{ }^{\circ} \mathrm{C}$. Thus, the first test contained 16 measurements in the frequency domain of impedance spectroscopy, which was controlled using IDAX 4.1 software in a portable laptop. At the end of the first test, an oil sample was taken from the electrode system, which was then prepared to apply a new sample of the same MOGUL oil before the second test. The electrode system was then prepared similarly to the first test.

The second test was started by turning on the temperature regulator and setting it directly to $90^{\circ} \mathrm{C}$. After reaching this temperature read from the thermometer, measurements were performed in the frequency domain with a gradual decrease of the temperature in steps of $10^{\circ} \mathrm{C}$ up to a temperature of $20^{\circ} \mathrm{C}$, i.e. a total of 8 measurements were obtained. The whole procedure of both tests was performed similarly on, in the order of the second tested, a sample of Shell DIALA S4 ZX-1 insulating oil.

All measurements in the first and second tests were performed at an applied voltage of $100 \mathrm{~V}$.

\section{ANALYSIS OF MEASURED RESULTS}

This section represents the measured experimental results of the investigated electrical insulating oils, subjected to two tests with different heating times to $90{ }^{\circ} \mathrm{C}$ and its effect on the existing humidity in the given 
insulating oils. From the measured complex model of the dielectric, the values of the real and imaginary part of the complex permittivity $\mathcal{E}^{*}$ in the frequency domain of impedance spectroscopy were obtained, which were subsequently converted to the values of the complex electrical modulus $M^{*}$, respectively it's a real and imaginary part, due to the more telling characteristics of the courses in the complex plane (so-called Cole-Cole graphs).

\subsection{Analysis of measured results of MO oil}

As already mentioned, the first test started by gradually increasing the temperature of the $\mathrm{MO}$ oil from $20^{\circ} \mathrm{C}$ to 90 ${ }^{\circ} \mathrm{C}$ and measuring the frequency characteristics with a temperature step of $10^{\circ} \mathrm{C}$. Fig. 2 shows the dependence of the real part of a complex electrical modulus in the frequency band at different oil temperatures MO. $M^{\prime}$ is actually the inverse of $\varepsilon^{\prime}$, which is directly proportional to the capacity ratio in the material. This graph signals the behavior of $M^{\prime}$ in the frequency spectrum with a gradual shift of the curves towards higher frequencies with increasing temperature. This shift is attributed to the increased conductivity of the material with increasing temperature. It follows from the above that the state of a given insulating oil can also be analyzed by means of $M^{\prime}$ as the position of the center of its curve in the frequency band.

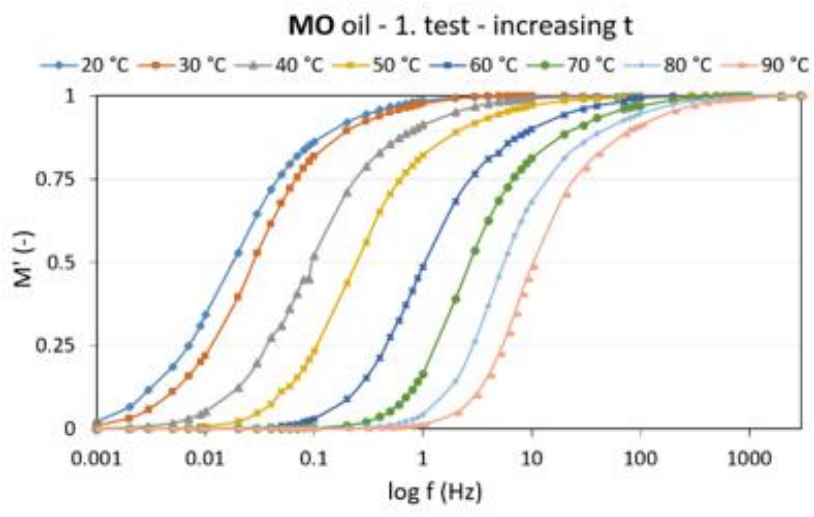

Fig. $2 M^{\prime}$ as a function of frequency as the temperature rises to $90{ }^{\circ} \mathrm{C}$ (MO oil)

The imaginary part of the complex electrical modulus $M^{\prime \prime}$, characterizing the dielectric losses, in the frequency band at different oil temperatures MO is shown in Fig. 3.

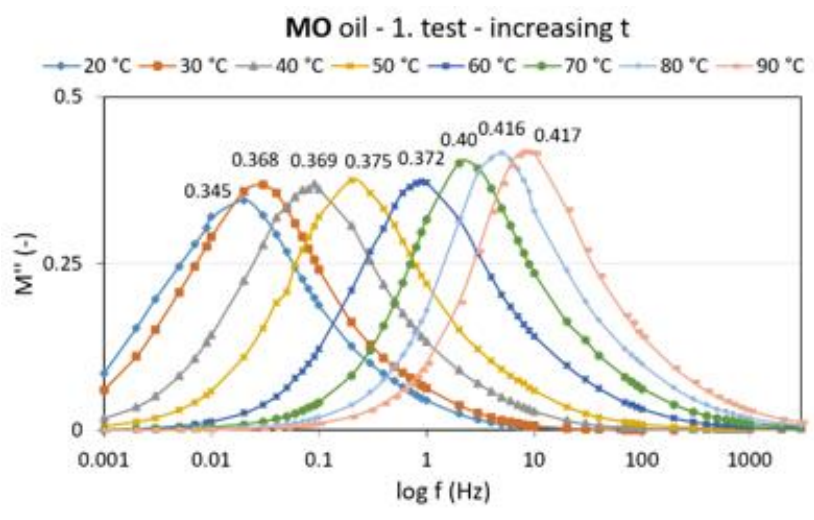

Fig. $3 M^{\prime \prime}$ as a function of frequency as the temperature rises to $90{ }^{\circ} \mathrm{C}$ (MO oil)
From these dependencies, as well as from the courses $M^{\prime}$, it is possible to see the shift of the curves, resp. their peaks in the frequency band towards higher frequencies with increasing temperature. This shift is related to the electron and orientation (dipole) polarization, which is strongly temperature-dependent, as the viscosity of the oil decreases as the temperature increases. From Fig. 3 is also to investigate the increase of the peaks of the curves with increasing temperature in the frequency spectrum. This increase in peaks can be attributed to the gradual degradation of moisture due to higher temperatures, as the peak apex approaches 0.5 , which represents ideal dielectric material courses with the only relaxation time considered by Debye.

The first test was then continued by measuring the backflow, i.e. gradually lowering the temperature back to $20{ }^{\circ} \mathrm{C}$. These characteristics will not be shown due to similar curves as in Fig. 2 and Fig. 3. However, the unspecified characteristics were measured to compare the two tests, comparing the rate of temperature rise to $90{ }^{\circ} \mathrm{C}$ and its effect (speed effect) on moisture in insulating oils. The second test consisted of direct heating of MO oil to 90 ${ }^{\circ} \mathrm{C}$ and gradual measurement in the frequency domain while lowering the temperature back to $20^{\circ} \mathrm{C}$.

The comparison of both tests yielded interesting results, in the form of a comparison of the influence of the $\mathrm{MO}$ oil heating rate on the temperature of $90{ }^{\circ} \mathrm{C}$, the real and imaginary part of the complex electrical modulus, which are shown in Fig. 4.

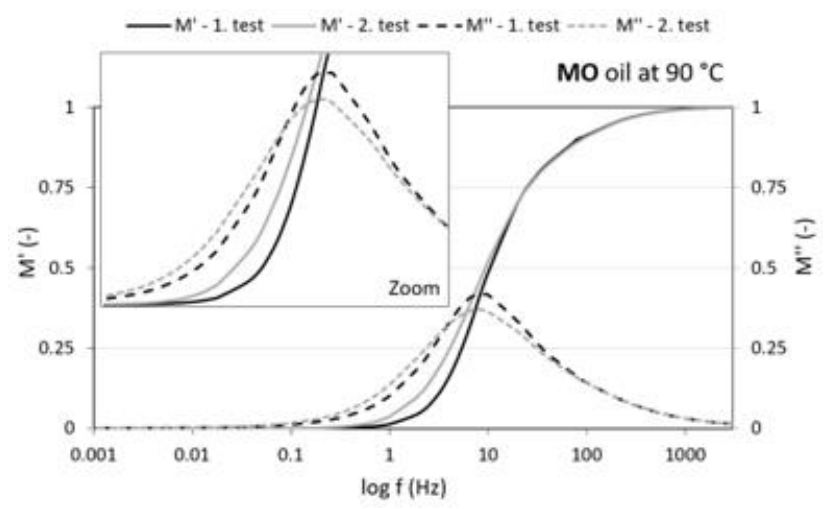

Fig. $4 M^{\prime \prime}$ and $M^{\prime}$ depending on frequency when comparing both tests (MO oil)

Fig. 4 is a comparison of both tests on $\mathrm{MO}$ oil at $90{ }^{\circ} \mathrm{C}$. Thus, the graph shows that the effect of faster heating of MO oil was reflected in the values of the real and imaginary parts of the complex electrical modulus. The curve $M^{\prime}$ (2nd test) was skewed towards lower frequencies due to the higher humidity compared to the curve $M^{\prime}$ (1st test). Thus, it can be argued that the effect of moisture is closely related to the distribution of relaxation times in the form of a deviation of the curve $M^{\prime}$ from its vertical axis through the center, as is well known from theoretical knowledge with the Cole-Cole distribution of relaxation times. It is similar in the case of $M^{\prime \prime}$, when the curves show a greater distribution of relaxation times, signaling a decrease in the peak of the curve $M^{\prime \prime}$ (2nd test) and an extension of the course in the frequency band. To confirm this hypothesis, both tests were compared by plotting the real and imaginary 
parts of the complex electrical modulus in the complex plane, which is shown in Fig. 5.

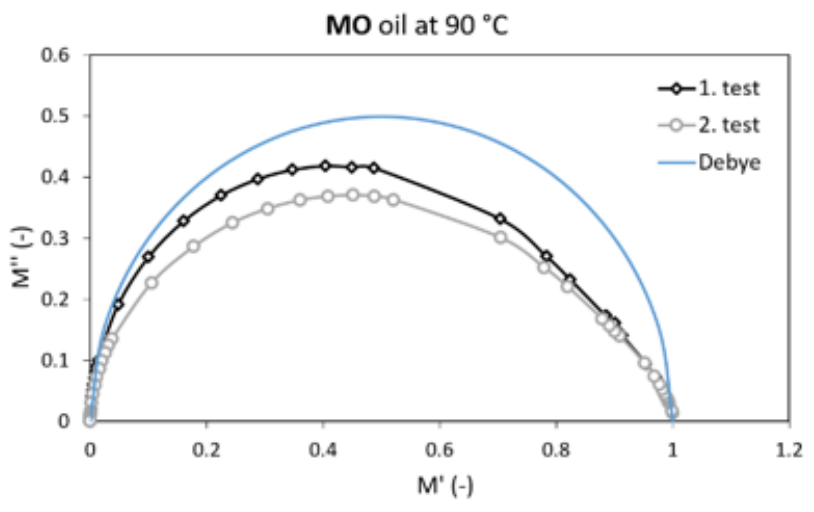

Fig. $5 M^{\prime \prime}$ and $M^{\prime}$ in the complex plane when comparing both tests (MO oil)

This graph shows that slower heating of the oil to $90{ }^{\circ} \mathrm{C}$ (1st test) eliminates the higher moisture concentration in the insulating oil MO than faster heating (2nd test). This is due to a greater shift of the center of the semicircle of the second test curve below the axis $M^{\prime}$, in other words, a decrease in the peak of the second test curve. The curve of the first test acquires the shape of a quasi-ideal dielectric (Debye curve) in the low-frequency region, symbolizing a perfect semicircle, but in the medium and higher frequency regions, its shape is deformed, resulting in some distribution of relaxation times characterizing the presence of polar substances in MO insulating oil.

\subsection{Analysis of measured results of SD oil}

Measurements, resp. the results of the SD insulating oil curves were plotted similarly to the MO insulating oil to investigate the behavior of the $M^{\prime}$ a $M^{\prime \prime}$ parameters of the SD oil as the temperature rise to $90{ }^{\circ} \mathrm{C}$ and to compare the two oil heating tests. Fig. 6 shows the dependence of the real part of a complex electrical modulus in the frequency band at different oil temperatures SD.

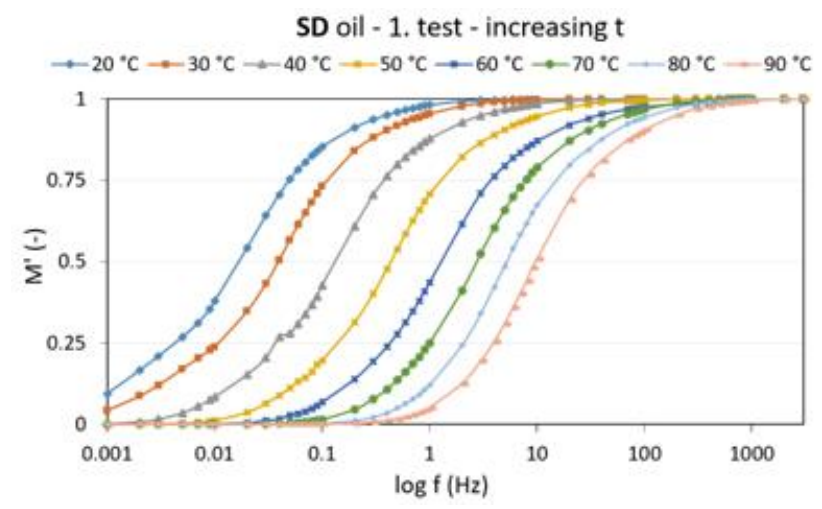

Fig. $6 M^{\prime}$ as a function of frequency as the temperature rises to $90{ }^{\circ} \mathrm{C}$ (SD oil)

This graph represents the behavior of $M^{\prime}$ in the frequency spectrum with a gradual shift of the curves towards higher frequencies with increasing temperature. This shift is attributed to the increased conductivity of the material with increasing temperature, similar to MO oil, but is to look for greater deviation of the curves in the frequency spectrum (vertical axis through the center more inclined to the sides), which can be attributed to poorer SD oil storage. The imaginary part of the complex electrical modulus $M^{\prime \prime}$ in the frequency band at different oil temperatures SD is shown in Fig. 7.

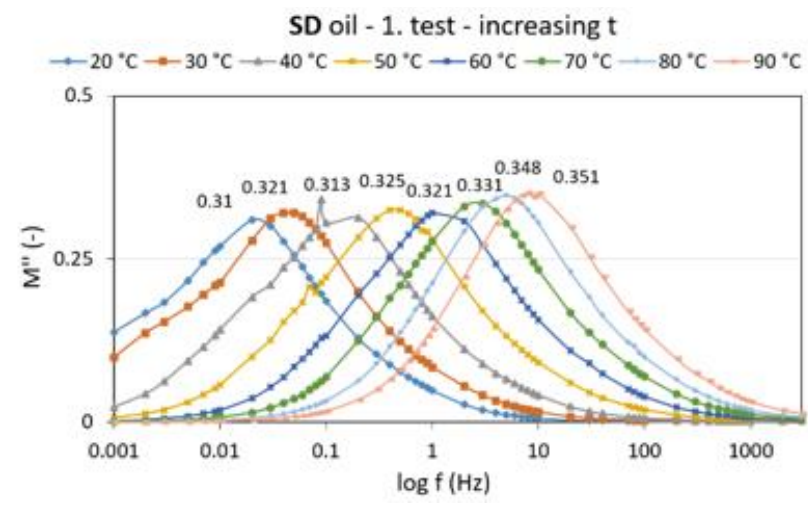

Fig. $7 M^{\prime \prime}$ as a function of frequency as the temperature rises to $90{ }^{\circ} \mathrm{C}(\mathrm{SD}$ oil)

The deflection of the curves $M^{\prime}$ of Fig. 6 was also transferred to the $M^{\prime \prime}$ curves in the form of a reduction in the peaks of the curves compared to the MO oil. This difference indicates a greater difference from the ideal values of $M^{\prime \prime}(0.5) \mathrm{SD}$ oil than for MO oil. In the SD oil, a similar increase in the peaks $M^{\prime \prime}$ in the frequency spectrum with increasing temperature can be seen as in the oil MO, which can be attributed to the gradual elimination of moisture in the oil SD.

Comparison of both SD oil tests yielded the same outputs as for MO oil, in the form of the values of the real and imaginary parts of the complex electrical modulus, which are shown in Fig. 8.

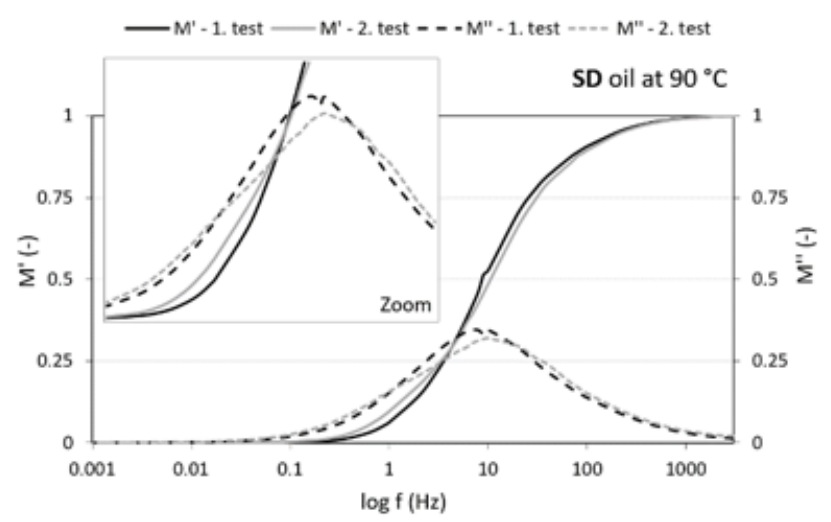

Fig. $8 M^{\prime \prime}$ and $M^{\prime}$ depending on frequency when comparing both tests (SD oil)

Fig. 8 is a comparison of both tests on SD oil at $90{ }^{\circ} \mathrm{C}$. Thus, the graph shows that the effect of faster heating of SD oil was reflected in the values of the real and imaginary parts of the complex electrical modulus. The $M^{\prime}$ curve (2nd test) was skewed in the frequency spectrum compared to the $M^{\prime}$ curve (1st test) due to higher humidity. It is also the case with $M^{\prime \prime}$, when the graph shows a larger distribution of relaxation times, signaling a decrease in the peak of the curve $M^{\prime \prime}$ (2nd test) and an extension of the course in the frequency band. Fig. 9 shows a comparison of both SD oil 
tests by means of a complex electrical modulus in a complex plane.

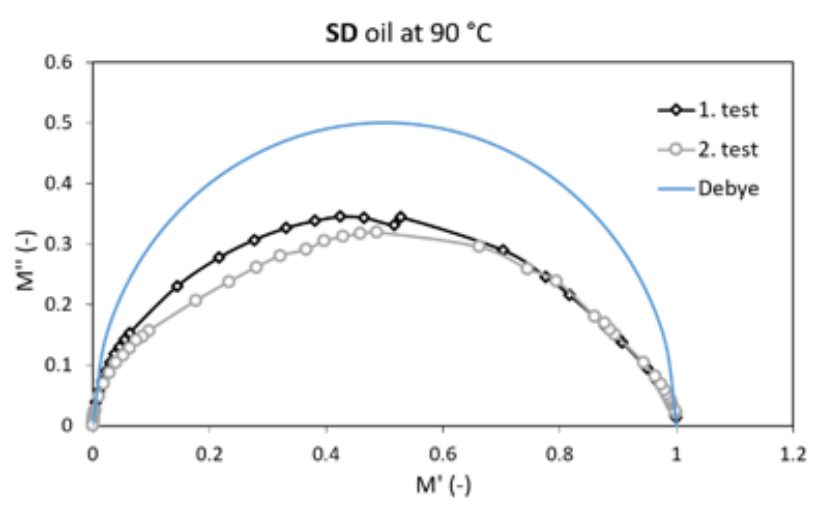

Fig. $9 M^{\prime \prime}$ and $M^{\prime}$ in the complex plane when comparing both tests (SD oil)

This graph also shows that slower heating of SD oil to $90{ }^{\circ} \mathrm{C}$ (1st test) eliminates a higher moisture concentration than faster heating (2nd test). This is due to a greater shift of the center of the semicircle of the second test curve below the axis $M^{\prime}$, in other words, a decrease in the peak of the second test curve. Thus, this graph shows the behavior of moisture in SD insulating oil and its influence on experimental measurements in the frequency domain of impedance spectroscopy.

\section{CONCLUSION}

This publication aimed to analyze the effect of the heating rate of two transformer oils to $90{ }^{\circ} \mathrm{C}$ through a complex electrical modulus in the investigated frequency band. It was found that faster heating of both oils (MO and $\mathrm{SD})$ is associated with a greater distribution of relaxation times in fluids. This fact is confirmed in Fig. 5 and Fig. 9 because the curves of the second test differed from the ideal Debye state of the dielectric more than the curves of the first test. This phenomenon could therefore be considered in practice as a consequence of a faster start-up of the transformer after a certain necessary shutdown.

\section{ACKNOWLEDGMENT}

The work was supported by the Ministry of Education, Science, Research and Sport within the project VEGA 2/0011/20 and 1/0154/21 and the Slovak Agency for Research and Development based on contract no. APVV15-0438, APVV-17-0372, and APVV-18-0160.

\section{REFERENCES}

[1] SINGH, S. - KUMAR, A. - SINGH, S. K. - JARIAL, R. K.: Dielectric response analysis and diagnosis of oil-filled power transformers calculation of paper moisture in power transformer, 2015 International Conference on Energy, Power and Environment: Towards Sustainable Growth (ICEPE), Shillong, India, pp. 1-4, July 2016.

[2] GUTTEN, M. - KORENCIAK, D. - JANURA, R. KOLTUNOWICZ, T. - ZUKOWSKI, P.: Measuring system for analysis of transformer moisture, 2018
ELEKTRO, Mikulov, Czech Republic, pp. 1-4, June 2018.

[3] MAHANTA, D. K.: Transformer Insulation Paper Moisture Measurement Using Optical Fiber Sensor, 2020 IEEE Region 10 Symposium (TENSYMP), Dhaka, Bangladesh, pp. 674-677, Nov. 2020.

[4] KOCH, M. - KRUGER, M.: A fast and reliable dielectric diagnostic method to determine moisture in power transformers, 2008 International Conference on Condition Monitoring and Diagnosis, Beijing, China, pp. 1-4, July 2008.

[5] CIMBALA, R. - HAVRAN, P. - BARTKO, P.: Comparison of behavior of electroinsulating oils using thermo-hysteresis dependencies, 2020 21st International Scientific Conference on Electric Power Engineering (EPE), Prague, Czech Republic, pp. 1-5, Dec. 2020.

[6] BARSOUKOV, E. - MACDONALD, J. R.: Impedance spectroscopy: Theory experiment and applications, New Jersey: John \& Sons Inc., 2005, pp. 608.

[7] PARAMO, MOGUL TRAFO CZ-A, Technical Data Sheet, Online: https://eshop.paramo.cz/data/VyrobkovaDokumentac e/ti_trafo_cza_z5.pdf.

[8] Shell Diala S4 ZX-1, Technical Data Sheet, Online: http://tdc.ge/wpcontent/uploads/2014/03/1_Diala_S4_ZX-I.pdf.

Received July 2, 2021, accepted September 6, 2021

\section{BIOGRAPHIES}

Peter Havran was born in 1994. In 2018 graduated (Ing.) at the Department of Electrical Power Engineering on the Faculty of Electrical Engineering and Informatics at Technical University in Košice. At present is a Ph.D. student in the Department of Electrical Power Engineering on the Faculty of Electrical Engineering and Informatics at Technical University in Košice. He received a master degree in electric power engineering on subject of the impedance spectroscopy of liquid insulation materials. His scientific research is focused on changes in electrophysical structure of insulation materials by dielectric respectively impedance spectroscopy.

Roman Cimbala was born in 1962. He graduated the Technical University of Košice, Faculty of Electrical Engineering and Informatics in Košice, in 1986. He received the Ph.D. degree in electrical engineering from the Slovak University of Technology in Bratislava, in 1994. He is Professor at the Technical University of Košice. His research interests concern: dielectric spectroscopy, diagnostics of HV systems.

Juraj Kurimský was born in 1967. In 1990 graduated (Ing.) at the Department of Electrical Power Engineering on the Faculty of Electrical Engineering and Informatics at Technical University of Košice. He received the Ph.D. 
degree in electrical power engineering from the Faculty of Electrical Engineering and Informatics at Technical University of Košice. He is Professor at Technical University of Košice. His research interests concern: discharges in transformers, analysis of partial discharges.

Jozef Király graduated (Ing.) at the Department of Electrical Power Engineering on the Faculty of Electrical Engineering and Informatics at Technical University of Košice in 2011. He received the Ph.D. degree in electrical power engineering from the Faculty of Electrical Engineering and Informatics at Technical University of Košice in 2014. He is an Assistant Professor at Technical University of Košice. His research interests concern: dielectric spectroscopy, diagnostics of HV systems.

Vladimír Kohan was born in 1994. In 2019 graduated (Ing.) at the Department of Electrical Power Engineering on the Faculty of Electrical Engineering and Informatics at Technical University in Košice. At present is a Ph.D. student in the Department of Electrical Power Engineering on the Faculty of Electrical Engineering and Informatics at Technical University in Košice. He received a master degree in electric power engineering on subject of the Utilization of FACTS devices to improve the transient stability of the power system. His scientific research is focused on Research of utilization of WAMS for power system control.

Jozef Humeník was born in 1994. In 2018 graduated (Ing.) at the Department of Electric Power Engineering on the Faculty of Electrical Engineering and Informatics at Technical University in Košice. He received a master degree in electric power engineering on subject of the Operation of HVAC distribution network depending on size of a capacity. At present is an external Ph.D. student in the Department of Electric Power Engineering on the Faculty of Electrical Engineering and Informatics at Technical University in Košice. His scientific research is mainly focused on design and researching Smart Grids. 